\title{
La experiencia del prácticum en educación infantil. Una narración en primera persona
}

\section{Practicum experience in early childhood education. A first-person narrative}

\author{
Victor Amar \\ Universidad de Cádiz \\ victor.amar@uca.es
}

Fecha de recepción: 09-09/2019

Fecha de aceptación: 23-11/2019

Amar, V., (2019). La experiencia del prácticum en educación infantil. Una narración en primera persona. Revista Practicum, 4(2), 60-76. https://doi.org/10.37042/practicum.2019.4.2.4 


\section{Resumen}

Las posibilidades de éxito del prácticum en educación infantil, que se cursa en tercero de carrera, son muy altas. No obstante, pueden existir circunstancias sobrevenidas al estudiante de magisterio que, en cierta manera, conviertan la experiencia formativa en un pretexto para crecer personal y profesionalmente. Para conocer y comprender su práctica nos valemos de la metodología narrativa. Es la forma más idónea que hemos encontrado para compartir su voz, otorgándole autoridad epistemológica y siendo un pretexto para mejorar a partir de su experiencia. Sus palabras nos llevan a comprender que ella quiere ser maestra, además de que se aprende en cualquier situación, pese a que su tutora esté en un contexto y con una realidad muy particular. La conclusión está en continua construcción pues la estudiante ha aprendido, desaprendido y reaprendido con el prácticum; dejando de ser una alumna de práctica para convertirse en una en práctica.

\section{Abstract}

The chances of success of the internship in early childhood education, which takes place in the third degree, are very high. However, there may be circumstances that may befall the teacher-training student, which in a way turn the formative experience into a pretext for personal and professional growth. In order to know and understand its practice, we use narrative methodology. It is the most suitable way we have found to share his voice, giving him epistemological authority and being a pretext to improve from his experience. Her words lead us to understand that she wants to be a teacher, and that she learns in any situation, even though her tutor is in a context and with a very particular reality. The conclusion is in continuous construction as the student has learned, disapproved and reappeared with the practice; from being a student of practice to becoming one in practice.

\section{Palabras claves}

Educación Infantil, Universidad, práctica pedagógica, narrativa.

\section{Keywords}

Early childhood Education, university, pedagogical practice, narrative, 


\section{Una introducción previa}

La experiencia del prácticum demanda cierta madurez en el alumnado. No vale con el simple hecho de estar habilitado según el expediente académico para cursar esta asignatura. Requiere de una clara lucidez madurativa. Por la sencilla razón de que se trata de una asignatura diferente a las anteriores, con unos requisitos e implicaciones que en poco se asemejan a las otras; a aquellas cursadas en la carrera de magisterio de infantil. Esta experiencia formativa cuenta con unas sensaciones de responsabilidad y toma de decisiones que invaden al alumnado de magisterio. En definitiva, una práctica que puede llegar a suscribir, o no, la verdadera vocación de ser maestro. Sobre la práctica en esta fase formativa (grado de educación infantil) existe una nutrida literatura científica planteándolo, incluso, como un espacio de aprendizaje (Casado, 2010; Latorre, 2011; Prados, Márquez y Pauda, 2018).

Ahora bien, en el panorama de las materias de estudio, el prácticum se consolida como una asignatura que aglutina el conocimiento que se ha de convertir en saber posicionado (García, 2016, p. 123-133). Una manera de poner en práctica y en valor lo estudiado en los dos primeros años de carrera; pues hemos de recordar que ésta se cursa en el segundo semestre del tercer curso. Posiblemente, sea el momento donde la mezcla de vocación y profesión se evidencia. En cierto modo, estamos ante una experiencia formativa que hace crecer en el conocimiento práctico de la profesión.

El aprendiz, en esta fase y momento, de la educación inicial básica irá a adquirir la dimensión sabia del officium. Algo que tendrá que ir desarrollando, paulatinamente, y que no puede quedar a merced de una sola experiencia. Ya que, se ha de realizar una verdadera inmersión con unos resultados en los diferentes ámbitos de la profesión.

Una práctica repleta de las mejores de las intenciones con la finalidad de dejar huellas para el futuro desarrollo profesional. Aunque puede darse el caso de que la fluidez comunicativa y la complicidad metodológica, en el amplio sentido de los términos, no se hayan dado entre el profesorado del centro y el estudiante de magisterio. Tal vez, no se trabaje de la manera en que el universitario deseara. O bien las relaciones con el profesor asignado y otras situaciones propias del centro no sean las mejores, perjudicando el proceso formativo. Es decir, estamos frente a un estudiante de magisterio que llega repleto de expectativas amparadas en el marco de los contenidos que se imparten en la facultad. Pero que entra en confrontación a partir de las diferencias marcadas por la teoría y la práctica. Sin soslayar del horizonte que ser docente, en una sociedad compleja, es una tarea ardua y complicada (Imbernón, 2017).

El universitario va adquiriendo la formación inicial en los diferentes momentos de su desarrollo profesional básico y, a la postre, es un resultado que lo habilita para su carrera, en la cual 
adquiere actitudes y valores para el desenvolvimiento del magisterio (Subirana, 2015). Pero, a la vez, aprende las funciones y conocimientos que podrá implementar en su labor en el aula. Evidentemente, estas cualificaciones las irá adquiriendo, poco a poco, a través del estudio, la reflexión y la práctica. Y, con todo, obtendrá un resultado aparente en el engrandecimiento de su formación, conocimiento y cultura; sin soslayarse la adquisición de aprendizajes psicopedagógicos y personales/experiencia. En definitiva, en su periodo formativo inicial irá adquiriendo conocimientos para posicionarlos en la complejidad creciente de los saberes y responsabilidades de esta profesión. Por consiguiente, en comprender el oficio de maestro de infantil.

Una vocación que requiere de formación. No se trata de aprender un oficio con estereotipos o recetas milagrosas. Aunque, en ocasiones, así lo demande el universitario para solucionar posibles situaciones de aula. Pero, luego descubrirá que en las ciencias sociales es complicada una extrapolación de situaciones, pues las condiciones propias de cada contexto lo determinan y lo hacen único.

En cierto modo, el estudiante de magisterio lo que adquiere en los primeros años formativos son fundamentos de una cultura profesional, además de resortes pedagógicos y didácticos para enfrentar y propiciar situaciones idóneas de enseñanza-aprendizaje (Fernández y otros, 2016; Trigo, 2016). Los contenidos ya están ahí y ahora lo que resta es desarrollar aquellos fundamentos que hagan bueno el saber cuándo y cómo pero, además del por qué usarlo en ese momento con determinado alumno o para aquel grupo-clase.

Es decir, en cierto modo, lo que se le facilita a los estudiantes de magisterio son apreciados conocimientos estratégicos que los irán a transformar, a partir de la práctica educativa, en unos supuestos conocimientos situados. Lejos de la teoría repleta de buenas intenciones se encuentra aquella entramada realidad, a veces, distante de la aprendida y aprehendida en los manuales universitarios.

Nuestro principio estratégico con respecto al prácticum no pasa por considerarlo como una simple asignatura. Sino, más bien, como un replanteamiento de las relaciones y contenidos expuestos, que se ha de reflexionar y no está exento de madurez, en la mencionada formación inicial. Estamos ante una experiencia de búsqueda de relaciones entre la teoría y la práctica, entre personas (Ballesteros, 2019). Y de lo que no dudaríamos es que el mencionado proceso está hilvanado en la más plausible de las intenciones educativas de interpretar e reinterpretar para mejorar la práctica educativa. Es decir, cambiar determinadas situaciones de inmovilismo por otras más flexibles e idóneas a partir de la entrada en el aula. De modo que, se disponga de una certera presentación, desarrollo y apropiación de la práctica en educación infantil.

\subsection{La importancia de la formación inicial}


La formación inicial es imprescindible (Domínguez y otros, 2015). Al igual que la inclusión de la práctica en este proceso. Estamos hablando de una formación teórica-práctica, donde los conocimientos teóricos pueden llegar a experimentar modificaciones y desarrollos posteriores. No vale con lo solo aprendido sino que se ha de insuflar capacidades en el estudiante de magisterio para que tenga capacidad de innovar y resolver. Estamos hablando y pensando, a la vez, en la necesaria vinculación de lo aprendido con las evidentes relaciones sociales y educativas que se dan cita en el aula y en el centro. $Y$, ciertamente, éstas se desarrollan en un espacio que al universitario en práctica no le pertenece, pues tiene su maestra o maestro en el colegio que conoce y asume la responsabilidad para facilitarle su labor.

En este sentido, cabría hacer avanzar esta idea, para que la experiencia formativa surta su mayor efecto y sea lo más efectiva posible. Y ahí, los seminarios previos previenen al estudiante en práctica de las posibles situaciones de disconfort que pueden acontecer. Un trabajo que se ha de hacer desde la reflexión y, además, desde la observación. No vale con intervenir en el aula llevado por la ilusión de saber, ya que puede ser engañosa y es "peor que la ignorancia" (Rossellini, 1979, p. 113). La intervención educativa se ha de llevar a cabo sedimentada en la experiencia de quien rige el aula. Pero, ¿qué sucede si esa persona no le permite intervenir, se muestra recelosa o se vale de una metodología que no coincide con la sensibilidad o su manera de entender la educación?

E, igualmente, suscitamos otra pregunta: ¿Cómo ha de actuar el futuro maestro en el caso de existir en el centro una situación de malestar que le pueda afectar? Del mismo modo que se le está habilitando en su formación con conocimientos o estrategias didácticas, desde recursos a materiales... ¿No creen que sería pertinente prepararle para la práctica; para el desarrollo de la práctica y que atienda desde la asertividad a la resiliencia? (Cyrulnik, 2009).

Si se le habla en las aulas de la facultad de sensibilidad a la diversidad, hemos de aplicarnos en primera persona esta cualidad. En la acepción de una diversidad que admita otras opiniones, actitudes o posturas de intervención (Balbás y Fernández, 2015). Y, con ello, contemplando diferentes resultados a los previstos. No estando reñida con el hecho de disentir por esa determinada acción con la que no se coincide; lejos de la obediencia o el paso servil por esta experiencia formativa.

En ocasiones, puede existir malestar en el estudiante con sus prácticas y puede no llegar a oídos del tutor de la facultad. Quedando la solución plasmada en las evidencias que se redactan o en algunas notas que aparecen explicitadas en la memoria final. Es decir, una vez que ya no se puede hacer nada o muy poco.

Por ello, promovemos que la experiencia formativa no sea solo de una estudiante de práctica sino en práctica. E insistimos en el matiz inclusivo de la preposición 'en'... Y, por consiguiente, se ha de 
incentivar el respeto a los profesionales y a la profesión. Antes que la obediencia o la admisión de una situación heredada. $Y$ todo ello empieza desde el momento en que se considera a la asignatura del prácticum no solo como una disciplina convencional sino, tal vez, como un momento de consideración a los planteamientos teóricos expuestos en la formación inicial, con una proyección práctica. En la cual ha de haber cabida a la reconsideración y a los replanteamientos, con respeto y argumentos. Es curioso como en los discursos teóricos de aula en la facultad se habla de supuestos de comprensión y respecto... Pero, ¿se cumple por parte de las personas implicadas? Es, por ello, que proponemos como pautas:

"(...) la elevación de la autoestima, el fortalecimiento de la confianza en sí mismos, la eliminación de ansiedades, la resolución de conflictos y el respeto de las personalidades diferentes, como apoyo a la construcción progresiva de la identidad de los sujetos escolarizados" (Martínez, 2005, p. 45-46).

\subsection{La labor de la práctica}

El prácticum es un momento formativo para la estimulación de posibles marcos de elaboración de trabajos y propuestas educativas. Pero ambos entornos de acción han de estar en contacto con la realidad del aula. $Y$ puede pasar por la imposibilidad de implementarlo o la discrepancia con la maestra responsable del aula. Sin embargo, el momento en que se puede decir algo será desde la memoria final de práctica, redactándose un buen trabajo garante y centrado en la realidad que se ha vivido; aunque hay casos que se pueden traducir en que se han, verdaderamente, padecidos.

Por ello, estamos intentando poner de relieve que la práctica ha de ser un momento para entender el hecho educativo desde su más absoluta complejidad (Hoyuelos, 2015). En la que hay que saber tomar decisiones y promover valores educativos pero, igualmente, modificar actitudes en beneficio del oficio y del grupo-clase. Se trata de un periodo de reflexión y de redacción de alternativas a las situaciones existentes. Que no han de ser, exactamente, adversas. Pero para las que han de estar preparados.

Y aquí el diálogo con el docente responsable del aula y el tutor de la facultad ha de ser continuo (Fisher, 2013). No se trata, tan solo, de confesiones personales sino de compresiones profesiones que le llevará a crecer en su carrera. En cierto modo, lo que estamos intentando argumentar es la idea de convertir el prácticum en una experiencia formativa que vaya más allá del periodo en práctica. Ya que la dimensión que se presume es la de aplicar en el aula lo aprendido en el proceso inicial. En consolidación con la importancia de conocer el contexto real de clase, además de las relaciones con los otros compañeros docentes, la dirección del centro y la administración educativa... Pero, igualmente, con la familia y el currículum (Gimeno, 2015). 
Es decir, en este periodo se hace imprescindible tener contacto con los docentes responsables de las prácticas. Incluso, se aconseja asistir a tutorías acompañando a la maestra para ver cómo se establece y dinamiza una tutoría, sea a nivel individual o grupal, con una intención informativa o formativa. En este sentido, en la faceta informativa destacamos observar el desenvolvimiento del intercambio fluido de la información pertinente para los familiares, sea a través de la verbalización puntual o la comunicación escrita (la redacción de una nota informativa). El matiz explicativo es fundamental, así como hacer crecer la sensibilidad y potenciar la participación de los familiares. En relación con el sesgo formativo, la propuesta se ciñe en atender a las dinámicas para organizar, por ejemplo, una escuela de padres y madres (Comellas, 2007), a través de programas, encuentros o tertulias pedagógicas. Un quehacer orientativo del cual el estudiante en práctica no debe quedar exento. E, incluso, tomando contacto, siempre que fuera posible, con el consejo escolar o el claustro; atendiendo a la manera de estar organizada la participación y la toma de decisiones. Una experiencia que pasaría por acompañar la coordinación de la etapa, por conocer las maneras de proceder y atender al desarrollo de las responsabilidades profesionales, dentro de un contexto y a tenor de la cultura docente que exista en el colegio. Sin soslayar el conocimiento del plan de centro o la posible planificación, además de acompañar los criterios y maneras de evaluar.

Una labor en práctica que se aglutinaría en la necesidad de comprender a las personas que forman parte de la institución educativa, además de conocer el marco curricular y legal donde se irán a desenvolver (Cabera, Funes y Brullet, 2004; Feito, 2011).

\section{Ideas sobre el método}

Llevados por la intención de conocer la experiencia vivida por una estudiante de magisterio en la asignatura del prácticum I, nuestro propósito de investigación se centra en: a) comprender su comportamiento ante una situación que dificulta el desarrollo personal y profesional durante su proceso formativo. $\mathrm{Y}$ b) atender a las relaciones humanas y cómo éstas calan en la cotidianeidad y pueden incidir en su periodo de prácticas.

Sobre este particular, la investigada es una estudiante que ha manifestado un alto grado de madurez. Con la particularidad de querer resolver lo mejor posible la situación adversa, de soslayo, que vive su tutora en la escuela; pues le afecta. Lejos de indagar en el origen de la situación, ella le da la vuelta a la problemática y plantea sacar provecho a estas circunstancias. Más allá de que le pueda gustar, o no, el contexto y la experiencia vivida. Continuando con este parecer, la alumna es una persona calmada en sus maneras, mostrándose segura ante sus decisiones. Es argumentativa y asertiva. Dice que antes que discutir me gusta escuchar a todas las partes, aunque en este caso, no he tenido ocasión. Lo que sí he 
podido es observar y ser testigo de situaciones que nada aportan a la educación y a mi formación. Igualmente, es comprensible y tiene reafirmada la decisión de ser maestra y, ahora, sabe de lo complicado de esta profesión donde las relaciones humanas son tan evidentes.

Con todo, la metodología cualitativa será nuestro referente. Así como la narrativa el modo de acceder a su parecer sobre cómo ha vivido su experiencia formativa en la práctica (Moriña, 2017). Estableciéndose el debate sobre cómo se sintió en vez de alumna en práctica, como una alumna de práctica. Una experiencia que le ha ayudado a crecer personal y profesionalmente. Y, por ello, su subjetividad será un aspecto imprescindible en la investigación. Ciertamente, daremos cobertura a las dos perspectivas fundamentales de la investigación cualitativa que según Sánchez (2004) son: conocer los contextos físicos y sociales.

La narrativa comparte la voz de la actuante y la erige en persona autorizada para dar a comprender (Landí y Sánchez, 2019). Del mismo modo que a través de la narrativa-biográfica aprendemos y visibilizamos la palabra de alguien que en este momento no conformaría parte de los discursos científicos disponibles. Una estudiante que llevó a cabo su prácticum I (asignatura obligatoria de tercero de la carrera de magisterio en educación infantil) en un colegio con una sola línea. Por lo que las maestras de esta etapa solo son tres, una por cada curso; aunque en el aula entren otras profesionales de la educación. Un colegio pequeño que tiene su continuidad con la etapa de educación primaria.

No sabemos con exactitud sí compartiendo su experiencia narrada estaríamos en condiciones de "transformar el mundo" (Rivas, 2009: 29). Tal vez, alimentamos la certeza de que el mundo no nos siga cambiando a su antojo. La idea de conocer y comprender mueve y promueve esta investigación con la presunción de contribuir, en la medida de nuestras posibilidades y que nunca se nos interprete como un gesto de vanidad, para mejorar el prácticum y que la profesión de maestro sea un poco más justa. Pero, insistimos en ello, la finalidad es la de "entender una vivencia" (Mariezkurrena, 2008: 231) y compartirla con el lector.

Igualmente, cabría añadir que el instrumento que utilizamos fue la entrevista semiestructurada (Kvale, 2011). Un momento empático generado a partir de preguntas y respuestas, inmerso en las premisas del procedimiento de la conversación. Según Vallés $(2007,37)$ : "El arte de la conversación, aprendido de modo natural durante la socialización, constituye el mejor fundamento conceptual y práctico para el aprendizaje de las diversas formas de entrevista cualitativa".

En este sentido, se establecieron tres tiempos en la entrevista, organizado a partir de tres grandes tópicos siempre relacionados con el antes, el durante y el después de su experiencia en las prácticas. A partir de alguna que otra pregunta inicial el debate se continuó por, aproximadamente, una hora por sesión. Asimismo, la disponibilidad y generosidad de la informante fue completa. Ahora bien, lo que 
pretendimos fue no abusar de su predisposición; además, hemos respetado su anonimato.

\section{Por unos resultados}

Una vez hemos conocido el método y a la informante, su parecer cobra especial relevancia. En un contexto poco habitual para las prácticas de magisterio, la chica narra que ha sido una experiencia muy peculiar. Al principio estaba muy ilusionada pero, poco a poco, me fui desinflando. No quise dejar de ir, por los niños. Pero hubo días que me sudaban hasta las manos. No podemos dejar de pensar en la estudiante. La situación, al parecer, era de malestar generalizado en el colegio. Los docentes no se llevaban bien entre ellos y como nos cuenta la informante: No había bandos, yo quería saber quién iba con mi tutora y quién iba en contra de ella. Pero eran como reinos de taifas. Cada uno por su lado. En un contexto de estas características es difícil empezar a sentirse a gusto y con predisposición para trabajar.

Unas relaciones laborales, completamente, rotas. Donde la maestra tutora se siente agobiada y a punto de desistir como docente. No obstante, da a entender que aguantará pues, en la voz de la informante, ya le queda muy poco para jubilarse. Y, en esta situación, de compromiso con la profesión se encuentra inmiscuida la futura maestra. No obstante, la propia estudiante de magisterio no tiene información de lo que ha sucedido y todo lo tiene que elaborar a partir de lo que observa. Desde el principio, las palabras no eran ofensivas y todo se traduce en un disimulo que roza la normalidad. Al parecer, Mi maestra estaba hecha polvo. Habían días que creo que llegaba después de haberse pegado un buen rato llorando. Y ante nuestra pregunta si había notado algo, su respuesta fue:

Nunca me comentó nada y nunca noté nada en particular. Me dijo que contaría conmigo para todo $y$, luego, he deducido que contó conmigo para sentirse apoyada y tener testigo de lo que le pudiera suceder. Pero, insisto, es una suposición.

Ante una situación de tal desagrado una joven ilusionada con la profesión de maestra entra en el colegio. Desde la teoría, en la facultad, se le hace hincapié en la importancia de las relaciones con los compañeros de profesión y que el diálogo es el hacedor para resolver los conflictos. Pero, en la realidad, los problemas están enconados y, al parecer, son irreversibles. Sobre este particular, ella se refiere como: Increíble. Yo notaba que no se miraban y que cada una iba a lo suyo. En principio lo vi normal. Pero, luego, me dije que estaba pasando algo. La estudiante, en una reunión a posteriori con su tutor/supervisor de la facultad, le comentó la situación pues todo se agudiza en el recreo, donde apenas había diálogo y se sentía sola. Mientras que otras compañeras del prácticum afirmaban que en la media hora del descanso se tomaban un café en la sala de profesores. Pero en mi caso, la mayoría de los días estábamos en la fuente, después íbamos a la fila y, directamente, a la clase. 
Ante esta situación nuestra pregunta no puede ser otra que relacionarla con lo qué aprendió. En este sentido, la chica hace alusión a:

¿Aprender? Destacaría lo mucho que ha significado para mí este proceso. Que más que enseñanza y aprendizaje ha llegado a ser de crecimiento personal. Ahora sé lo que no quiero que me hagan. No lo permitiría y creo que no lo permitiría con otros compañeros y compañeras.

Dice que sería capaz de denunciarlo hasta en los medios de comunicación. Habla de una situación deshonesta entre compañeras. Señala lo bonito de esta profesión pero somos, a veces, los profesionales los que no sabemos comportarnos como personas de la educación. Y hacemos hincapié en mantener la expresión "personas de la educación" pues, seguidamente, realiza la apreciación de personas con educación.

Apunta a que no cambiaría la práctica en ese colegio y con esa maestra. Se refiere a ella como una gran profesional. Probablemente, su comportamiento se debe a que ya viene de vuelta de todo. La práctica ha sido un reforzamiento de lo que me gustaría ser de mayor. Y sigue diciendo que:

He aprendido más de lo que en un principio creía que iría a ser mi practicum. He visto en el aula desde un conflicto entre los alumnos y como la maestra lo ha resuelto con una asamblea, permitiendo exponer a todas las partes sus hechos y pareceres. $Y$, también, he visto fuera del aula situaciones de relativa tensión.

Con todo, la estudiante mantiene que su experiencia ha sido muy positiva. Desde hacer una nota informativa hasta estar presente en un debate, con tintes de discusión, ante un grupo mayoritario de padres y madres muy preocupados por una situación delicada que podría afectar, directamente, a sus hijos.

Por otro lado, mantiene que la maestra le permitió en todo momento tomar iniciativas en el aula. Tan solo requería de un poco de convencimiento. Ella quería que le explicara las cosas antes de hacerlas. Al parecer, la compenetración entre ambas fue muy acertada. Tal como se pone de manifiesto en:

Aunque, sin discutir con ella, en varias ocasiones, me desaconsejó hacer unas actividades en el patio. En principio, no lo entendí y así lo reflejé en la memoria y lo que hice fue proponerla como una evidencia de aula. Pero ahora, lo entiendo.

El patio era el lugar de encuentro de las clases. Y, a la vez, el espacio de recreo para los alumnos en donde se evidenciaban las relaciones humanas entre las compañeras. En este caso, los vínculos estaban rotos y era mejor programar solo dentro de la clase, con nuestros niños.

A todas luces, la futura maestra comienza a saber diferenciar entre teoría y práctica. $Y$ consigue distinguir, perfectamente, entre querer y poder. Suscribe que he madurado mucho con la situación que se vivía en el colegio. Y continúa diciendo que, igualmente, he sufrido mucho. Me iba a mi casa y, a veces, lloraba de impotencia. No 
entendía por qué se le marginaba. Para concluir con: Al final, se perjudicaba a toda la clase y los niños no tienen culpa de nada. La estudiante de magisterio se refiere a que cuando se organizaba una salida, la única clase que no salía del centro era la suya y ese día el patio era un desierto; llegué a pensar que sucedía así porque eran los más pequeños. Al parecer, y según la informante, la dirección lo sabía.

Ante esta situación preguntábamos por sí el tutor de la facultad le propuso cambiar de maestra. A lo que ella contestó que: Sí, pero no iba hacerlo pues me gustaba su forma de trabajar $y$ conmigo siempre se portó muy bien. Y, seguidamente, le volvimos a preguntar desde otra perspectiva: ¿Pero cómo aguantaste? Y la sencillez de la respuesta se ancló en nuestro discurso: Pues supe desde el comienzo que ella veía en mí mis ganas de ser maestra de infantil.

La formación inicial, de la cual forma parte el prácticum, conforma una secuencia de situaciones de aciertos y posibles errores. Sobre esto último la maestra siempre aconsejo a la joven. En este sentido, la chica se refiere al error como parte del proceso; lo que debemos evitar son los errores irreversibles. Y, está claro que le preguntábamos sobre qué podría ser eso de 'los errores irreversibles'. Sobre este particular, la contestación se dirigía sobre las cosas que no se han aclarado y creerse que todos están contra de una. Más seria de lo habitual, la informante comenta que han debido pasar cosas muy desagradables. Prefiero no saberlas. Nunca las he pregunta y nunca ella me dijo nada. Lo peor es que se han normalizado estas relaciones anormales.

La veterana maestra es una persona con resiliencia. Se trata de una luchadora que aguanta y disimula. $Y$ tras un proceso de cambio, no vuelve al punto de origen sino que reaparece transformada. Una iniciativa que podemos estar de acuerdo, o no, con ella. Pero cabría decir que jamás mezcló las cosas. Supo diferenciar y a lo mejor, las otras maestras, tenían menos pudor a la hora de disimular la antipatía. La estudiante de magisterio siempre se refiera a ella como una persona educada. No es que fuera poquita cosa; es que su carácter es así. De no querer complicarse la vida o estar en un lía-lía.

La estudiante en prácticas dice que ha hablado mucho con su maestra sobre educación. Que siempre la ha respetado. Sostiene que su práctica ha sido un proceso que la ha engrandecido y no 10 cambiaría por nada del mundo. Ya que: Ahora no solo he aprendido a ser un poco mejor maestra sino que, también, mejor persona. Y mantiene que los niños son lo más importante pero que los familiares han de estar ahí. No son padres o madres de quita y pon. Hemos de contar con ellos desde el principio al final del curso; son parte activa. Y dice que: ahora no los veo como teoría sino como una posible realidad en el aula.

Al cuestionamiento de cómo vivió la experiencia del prácticum, no duda en responder con un rotundo no lo cambiaría; aunque no sé 
si estaría preparada para el año próximo vivir la misma experiencia. Y matiza que mejoraría el sistema de elección del centro y la tutora, pues la asignación es casi al azar y se debería conocer más a la persona con la que vamos a trabajar. Ya que, es mucha la responsabilidad, que se asume, tanto personal como profesionalmente, en base a una relación nada o poco consolidada.

Estamos ante una maestra quemada 0 , al menos, desilusionada por diversas circunstancias. Pero, igualmente, la alumna en práctica se refiere a que le comentaba persistentemente: la cantidad de papeles que hay que rellenar en el programa Séneca. Y continuaba con ni te cuento lo que hay que aguantar. Poniendo de manifiesto que la jubilación podría ser su tabla de salvación.

\section{Conclusiones}

Tras este recorrido por un supuesto entramado teórico, repleto de buenas intenciones acompañadas de citas bibliográficas. Después de una sucinta argumentación del porqué de la metodología narrativa en este modelo de investigación sobre el prácticum. Y una vez hemos compartido la voz de la informante, estamos en condiciones de establecer algunas conclusiones. Tal vez, antes de dar entrada a éstas, no estaría de más determinar que no son concluyentes. Pues las hemos elaborado como un resorte de planteamientos bienintencionados que, en vez de dar por finalizada la reflexión, mantienen el propósito de continuarlas.

En este sentido, las hemos redactados como unas conclusiones a modo de desenlacen que invitan a proseguir leyendo, reflexionando y aprendiendo sobre el prácticum en el grado de magisterio en infantil. Además, de continuar dándole protagonismo a la estudiante. $Y$ no relegarla a que esto sea una experiencia solo formativa sino que vire en un quehacer para su crecimiento personal y profesional. Un modo de conocer y reconocerse en la profesión. Una forma de crecer en este oficio que tanto exige estar bien preparados y ser personas con una alta tasa de sensibilidad y responsabilidad. Quizás, sea el modo que hemos encontrado en establecer la diferencia entre ser un buen o mal docente de infantil.

La formación inspirada en el estudio ayuda, y mucho, al futuro maestro en su desarrollo profesional. Una formación inicial que se continuará con la formación permanente (Fuguet, 2007). Ahora bien, el quehacer reflexivo le beneficiará para el desarrollo de la creación de su propia teoría, a la vez, que le ayudará en la aprobación y validez de su labor en el aula. Pero, igualmente, la práctica le hará bien en sus planteamientos para crecer en la faceta humana y profesional.

A todas luces, el prácticum en esta estudiante de magisterio le ayudó en su crecimiento, tal como hemos narrado pero, no deja de ser, un punto y seguido en su formación. Tal vez, la manera más pertinente que pueda existir para romper la rutinización de la enseñanza-aprendizaje que se proporciona en el seno de la facultad. 
En este momento, el prácticum se erige como el modo de aprender centrado en la acción reflexiva (Perrenoud, 2007). Es decir en aprender, sintiéndose coprotagonista, desde la acción y atendiendo a sus posibles consecuencias. Un aprendizaje situado en su contexto, con y entre personas.

El prácticum es el modo más idóneo de aterrizar en la experiencia profesional. Es darle curso a las posibles y más comunes problemáticas que se pueden producir en el seno y fuera del aula. Sean de tipo disciplinario o de motivación con el alumnado. En definitiva, es sentirse en un entorno real de aprendizaje, resolviendo aspectos cotidianos como la falta de aquel material, poner en valor determinado método de enseñanza $y$, sobre todo, atender a la diversidad. Además de conocer en primera persona las opiniones sobre la sobre carga de trabajo y responsabilidades que se le atribuyen a los maestros. Sin soslayar lo destacable que es comprobar los matices que existen en las relaciones laborales e, igualmente, tener presente lo importante que es contribuir a un buen ambiente con los familiares, inspirado en el respeto mutuo, la escucha o el diálogo. Y todo en el crisol de las pedagogías del y para el siglo XXI (Carbonell, 2015).

No lejos quedaría todo lo relacionado con el trabajo burocrático y la relación con la dirección y la administración educativa. No es baladí que se hable, extensamente, sobre el maestro quemado. A las consabidas responsabilidades de aula, se le han de aunar otras tantas de organización y seguimiento, que pasan por sistemas informatizados que en forma y tiempo exigen una concreción escrupulosa. Estamos hablando de la hiperregularización burocrática que agota o presiona al docente. Aquí la resiliencia se erige como la capacidad de sobreponerse ante la adversidad.

Junto al burnout o síndrome del docente quemado, hay que tener presente el mobbing $u$ hostigamiento que acaba en acoso persistente $y$, en muchos casos, de forma encubierta (Rodríguez, 2013; Esteras, Chorot y Sandín, 2018). Sin eludir que en momentos concretos pueden llegar a generar situaciones de agresión física o verbal, o bien promover aislamiento con el consabido desgaste psicológico. En ocasiones muy determinadas, aparece el conocido bossing o acoso vertical del que tiene el poder hacia los otros trabajadores, propiciando situaciones muy desagradables.

El profesor quemado sufre $y$, a veces, su malestar es notorio. Se traduce en un vacío evidenciado a manera de agotamiento de los recursos personales, que va desde los físicos a los mentales, que quiebra cualquier intención por alcanzar determinada expectativa. La desgana se apodera del proceso y termina perjudicando, profundamente, las relaciones humanas con una apatía que lo invade todo, o bien se traduce en una corrosión que lleva a situaciones enfermizas. En el docente se rompen las relaciones humanas y se genera una despersonalización llegándose a anular o encapsular. Incluso, se puede producir un espectacular reduccionismo a nivel personal que tiene una importante determinación en el ámbito 
laboral; pues termina con una importante pérdida de confianza y promoviendo, en ocasiones, un autoconcepto negativo de la profesión. Y tal como propone Rossellini (1979: 50) se ha de incentivar "Una educación que permita eliminar todas las ideas falsas, todos los prejuicios, todo cuanto nos aleja de la verdad, y barrer la hojarasca de sugestiones malsanas, de egoísmos, de vanidades y de celos que nos asalta".

Con todo, el futuro maestro está en práctica y no se ha de dejar invadir por todos las connotaciones negativas que la profesión pueda llegar a tener. La labor del tutor/supervisor desde la facultad ha de ser la de reconducir la mirada. Saber explicarle que eso existe y que está ahí. Pero que no ha de reproducir ese modelo insano. Antes de llegar a una situación tan indeseada como la desidia o el rechazo a la profesión de maestro, el diálogo y la ayuda por parte de especialistas, compañeros o sindicatos pueden ser de gran ayuda.

La experiencia que ha atesorado la futura maestra es crucial. No solo se ha enfrentado a la realidad del aula sino que ha compartido con una profesional su experiencia. La ficción dibujada o descrita en los apuntes de clase se da de bruces con esta evidencia que desgarra, pero que le hace crecer. Claro está que el debate se genera a partir de si se está produciendo en el momento oportuno y con la intensidad deseada. No obstante, la interpretación que obtenemos es que su crecimiento ha sido diferente a los de sus otros compañeros de las prácticas. Ella ha asumido la responsabilidad de maestra en práctica y la de maestra (con mayúsculas), por las circunstancias que ya se pueden imaginar.

Una experiencia acumulada en la cual tuvo que saber redactar una nota informativa por una simple pediculosis y acompañar una reunión grupal con un claro componente explicativo por un motivo serio de salud en el centro. Pero, igualmente, a continuación de la reunión y la preocupación de los familiares, organizó junto con la maestra, una mesa redonda donde acudió la dirección del centro y una representante de la consejería de salud que, tras la exposición de los hechos, se debatió y se aclaró que no había mayor riesgo para el resto de compañeros de aula o del centro.

Una experiencia más allá de lo que en principio uno podría solicitar para el prácticum, ya que no pudo elegir a su tutora (y mucho menos las circunstancias en la que ella estaba); que no logró comunicar con su tutor de la facultad estas dificultades vividas en el aula. Sin embargo, llegó a suscribir el poder del diálogo. Comenzó a considerar al patio como un verdadero espacio para aprender con los alumnos y de los compañeros de profesión. E, incluso, se sensibilizó de lo que no se debe hacer o permitir como maestra. Mientras advirtió y admitió que la familia forma parte imprescindible del engranaje de la educación.

Pero las circunstancias fueron las narradas y la opinión de la informante fue: Me hubiese gustado tener un prácticum como el resto de mis compañeros. Pero ahora, y después de todo, me alegro de lo 


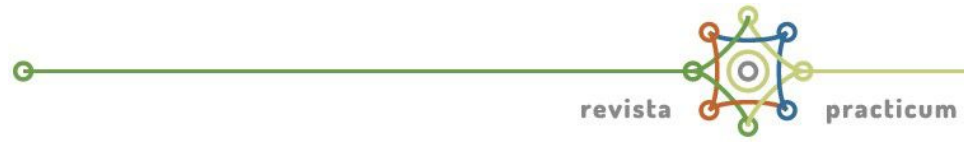

mucho que he aprendido. Y se reafirma en un rotundo: Quiero ser maestra de infantil.

Ciertamente, aquel dicho que el aprender no ocupa lugar, no lo vayamos a discutir. Pero sí resta tiempo y hasta puede llegar a desgastar. Lo que no se ha de permitir es que, en relación con la universitaria, exista una invasión más allá de lo pertinente en las prácticas por parte de las problemáticas personales y en el centro. Además de que las responsabilidades excedan, como hemos corroborado, al alumnado en práctica. Pues estos estudiantes están en construcción dependiendo, todavía, de su formación inicial como futuros docentes (Vaillant y Marcelo, 2015). Y aquí hay que incentivar el desaprender... como aquello que no te vale para la vida, para la profesión de maestro. Y eso es lo que ha hecho nuestra informante: aprender pero, igualmente, desaprender y reaprender... con la práctica...

\section{Referencias bibliográficas}

Balbás, M. y Fernández, J. (2015). Atención a la diversidad en el Aula de Educación Infantil. Madrid: Paraninfo Universidad.

Ballesteros, B. (2019). Investigación social desde la práctica educativa. Madrid: UNED.

Cabrera, D.; Funes, J. y Brullet, C. (2004). Alumnado, familias y sistema educativo: Los retos de la institución educativa (La escuela del nuevo siglo). Barcelona: Octaedro.

Carbonell, J. (2015). Pedagogías del siglo XXI: Alternativas para la innovación educativa. Barcelona: Octaedro.

Casado, A. (2010). Aprender a ser maestro: creencias de los estudiantes de Magisterio sobre la interacción en el aula. Cuenca: Universidad de Castilla-La Mancha.

Comellas, M. (2007). Escuela para padres: Las claves para educar a nuestros hijos. Barcelona: Ariel.

Cyrulnik, B. (2009). La resiliencia. Una infancia infeliz no determina la vida. Barcelona: Gedisa.

Domínguez, M.; González, R.; Medina, M. y Medina, A. (2015). Formación inicial del profesorado de Educación Infantil: claves para el diseño innovador de planes de estudio. Revista Ensayos, 30(2), 227-245. https://revista.uclm.es/index.php/ensayos/article/view/826

Esteras, J.; Chorot, P. y Sandín, B. (2018). El síndrome de burnout en los docentes. Madrid: Pirámide.

Feito, R. (2011). Los retos de la participación escolar. Elección, control y gestión de los centros educativos. Madrid: Morata.

Fernández Díaz, M.J., Rodríguez Mantilla, J.M. y Fernández Cruz, F.J. (2016). Evaluación de competencias docentes del profesorado para la detección de necesidades formativas. Bordón. Revista de Pedagogía, 68(2), 85-101. 
Fisher, R. (2013). Diálogo creativo. Hablar para pensar en el aula. Madrid: Morata.

Fuguet, L. (2007). La formación permanente: Una vía para mejorar la calidad de la Educación Infantil. Revista de investigación, 31(62), 107-124.

García, M.L. (2016). El Prácticum en la formación inicial del maestro. En S. Nieto (Ed.). Competencias del profesional docente (123-133). Madrid: Dykinson.

Gimeno, J. (2015). Ensayos sobre el currículum: teoría y práctica. Madrid: Morata.

Hoyuelos, A. (2015). Complejidad y relaciones en educación infantil. Barcelona: Octaedro.

Imbernón. F. (2017). Ser docente en una sociedad compleja: La difícil tarea de enseñar. Barcelona: Graó.

Kvale, S. (2011). Las entrevistas en investigación cualitativa. Madrid: Morata.

Landí, Ma. y Sánchez, S. (2019). El método biográfico-narrativo. Una herramienta para la investigación educativa. Educación, XXVIII(54), 227-242.

Latorre, M. (2011) El prácticum como espacio de aprendizaje profesional para docentes en formación. Revista de Docencia Universitaria, 9(2), 35-54. https://doi.org/10.4995/redu.2011.6157

Mariezkurrena, D. (2008). La historia oral como método de investigación histórica. Gerónimo de Uztariz, 23/24, 227-233.

Martínez, J.B. (2005). Educación para la ciudadanía. Madrid: Morata.

Moriña, A. (2017). Investigar con Historias de Vida: Metodología biográfico-narrativa. Madrid: Narcea.

Prados, M.; Márquez, M. y Pauda, D. (2018). Otra pedagogía en movimiento: Dialogando con la experiencia en la formación. Almería: Universidad de Almería.

Perrenoud, P. (2007). Desarrollar la práctica reflexiva en el oficio de enseñar. Barcelona: Graó.

Rivas, I. (2009). Narración, conocimiento y realidad. Un cambio de argumento en la investigación educativa. En Rivas, I.; Herrera, D. (Coord.). Voz y educación. La narrativa como enfoque de interpretación de la realidad (pp.17-36). Barcelona: Octaedro.

Rodríguez, N. (2013). Del mobbing al burnout. Barcelona: Océano Ambar.

Rossellini, R. (1979). Un espíritu libre no debe aprender como esclavo: escritos sobre cine y educación. Barcelona: Gustavo Gili. UNED.

Subirana, V. 2015. La pedagogía transformadora. Madrid: 
Trigo, E. (2016). El papel de la formación inicial y permanente del profesorado para forjar lectores. RESED, 4, 66-84. http://xurl.es/w4bbo

Valles, M. (2007). Entrevistas cualitativas. Madrid: Centro de investigaciones sociológicas.

Vaillant, D. y Marcelo, C. (2015). El ABC y D de la Formación Docente. Madrid: Narcea. 